\title{
An observational study of safe and risky practices in funeral homes in South Africa
}

\author{
A Ringane, ${ }^{1}$ BA Hons; M Milovanovic, ${ }^{1}$ MA; D Maphakula; ${ }^{1}$ F Makete; ${ }^{1}$ T Omar, ${ }^{2}$ MB BCh, MMed; \\ N Martinson, ${ }^{1,3}$ DCH, MFGP, MPH; L Lebina, ${ }^{1}$ MB ChB, Dip HIV Man (SA), MPH \\ ${ }^{1}$ Perinatal HIV Research Unit, South African Medical Research Council; and Soweto Matlosana SAMRC Collaborating Centre for HIV/AIDS \\ and TB, Faculty of Health Sciences, University of the Witwatersrand, Johannesburg, South Africa \\ ${ }^{2}$ Department of Anatomical Pathology, National Health Laboratory Service and Faculty of Health Sciences, University of the Witwatersrand, \\ Johannesburg, South Africa \\ ${ }^{3}$ Center for TB Research, Johns Hopkins University, Baltimore, Md, USA
}

Corresponding author: M Milovanovic (milovanovicm@phru.co.za)

\begin{abstract}
Background. Funeral home personnel are at risk of exposure to infectious hazards. The high prevalence of infectious diseases in South Africa means that these workers and family members of deceased individuals are vulnerable to infection if proper safety measures and equipment are not used.

Objectives. To collect observational information on funeral industry practices in order to assess the safety of handling corpses and exposure to risk that could result in disease transmission.

Methods. A cross-sectional study was conducted across two locations from August to October 2015. Funeral homes in Klerksdorp and Soweto were approached. The study team did facility assessments and observed preparation practices, focusing on safety equipment, personal protective equipment (PPE) and contact with hazardous materials. Interviews with funeral home personnel and relatives of the deceased were also conducted.

Results. Of the funeral homes, 23.0\% (20/87) agreed to participate. A median of 5 personnel (interquartile range 4 - 8) were employed per facility. It was observed that not all PPE was used despite availability. Gloves, aprons and face masks were most commonly worn, and no personnel were observed wearing boots, gowns or plastic sleeves. Funeral homes were located near food outlets, schools and open public spaces, and not all had access to proper biohazardous waste disposal services. Of 5 family members who were interviewed for the study, none reported being willing to partake in the funeral preparation procedure.

Conclusions. There is a need to standardise the use of safety equipment, waste disposal methods and location designation in the funeral industry.

S Afr Med J 2019;109(8):587-591. DOI:10.7196/SAMJ.2019.v109i8.13523
\end{abstract}

Personnel working in the funeral services sector are at risk of exposure to infectious hazards transmitted by inhalation of aerosolised body fluids, direct inoculation and mucocutaneous contamination. ${ }^{[1-3]}$ Viruses and bacteria that can spread post mortem include methicillin-resistant Staphylococcus aureus, hepatitis B and $\mathrm{C}$ viruses, severe acute respiratory syndrome-related coronavirus, prions, HIV, Mycobacterium tuberculosis and Ebola virus. ${ }^{[1,4]}$ A recent study by Correia et al. ${ }^{[5]}$ found that tuberculosis (TB) can remain viable for up to 36 days after death,$^{[5]}$ and exposure can occur through fluid build-up in a corpse and the expelling of residual air when it is moved. ${ }^{[2]}$ Previous studies have documented cases of HIV seroconversion in personnel working with corpses due to exposure to blood or body fluids and injuries from needles and sharps. ${ }^{[1,6,7]}$

With the recent 2018 Ebola outbreak in the Democratic Republic of Congo ${ }^{[8]}$ and the 2014 outbreak in West Africa, which had claimed more than 8304 lives (by 7 January 2015) out of 21121 reported cases ${ }^{[9]}$ it has become clear that some funeral traditions (touching, kissing, washing of the corpse) are high-risk practices that can spread the virus. ${ }^{[10]}$ In response, the World Health Organization released guidelines on how to contain and bury corpses of people who had fallen victim to Ebola or Marburg virus disease by wearing personnel protective equipment (PPE) when handling the corpse and contaminated materials..$^{[1]}$

While South Africa (SA) has not yet had any reported cases of Ebola, there have been cases of other viral haemorrhagic fevers. ${ }^{[12]}$
The country also has a high number of deaths attributable to infectious and parasitic diseases (19.5\% of deaths, $89727 / 460236$, in $2015)^{[13]}$ and some of the highest numbers of deaths from TB (33 063 in 2015) ${ }^{[13]}$ and/or HIV (180 000 in 2015 $)^{[14]}$ globally. By collecting preliminary observational information on safety procedures and risky practices in funeral homes, we hoped to provide insight into the potential for infectious diseases transmission in the funeral services sector.

\section{Objectives}

The high prevalence of infectious diseases in SA means that funeral industry workers and family members of deceased individuals are vulnerable to infection if proper safety measures and equipment are not used. The objective of this study was to collect observational information on funeral industry practices across two locations in order to assess the safety of handling corpses and exposure to risk by recording types of safety equipment used, frequency of their use, procedures followed, and frequency of coming into contact with potential contaminants that could result in disease transmission.

\section{Methods}

The funeral home study was carried out in two locations: Soweto, Gauteng Province, and Klerksdorp, North West Province. The two locations were chosen because they varied by population density and urban-rural classification. Soweto is located in the south-western 
outskirts of the City of Johannesburg Metropolitan Municipality. According to the most recent SA census, there were $\sim 1.5$ million people living in Soweto in 2011, $30 \%$ of Johannesburg's total population. ${ }^{[15]}$ Klerksdorp is located in the Matlosana subdistrict of Dr Kenneth Kaunda District, North West. At the time of the census, Matlosana had an estimated total population of 398676 people, of whom $92 \%$ were classified as urban and $8 \%$ as rural. ${ }^{[16]}$ Of the 460236 deaths reported in SA in 2015, 21.3\% ( $n=98$ 191) occurred in Gauteng and 7.6\% $(n=34428)$ in North West. ${ }^{[13]}$ Both HIV and TB are in the top 10 causes of death in the two provinces. ${ }^{[13]}$

We completed a cross-sectional study from August to October (winter-spring) 2015 in these two locations. A database of existing funeral homes across the two locations was developed using previous study records, ${ }^{[17]}$ the telephone directory, advertisements of funeral homes in the areas, and field trips. A total of 87 funeral homes were identified and appointments for study enrolment were scheduled following a site visit. Consenting funeral homes were visited by the study team a minimum of two times to conduct facility assessments and observe preparation practices focusing on safety equipment, PPE and contact with hazardous materials. We also conducted interviews with funeral home personnel and relatives of the deceased.

The primary outcomes of the facility assessments were to record their location, size and infrastructure and safety practices, and the availability of PPE. Each facility was assessed once. Participating funeral homes were requested to contact the study team once a possible corpse was identified that met the study inclusion criteria (age $>18$ years and died from natural causes or minor trauma). Two study team members visited the funeral home to observe how the corpse was prepared for burial. The outcome of the process mapping was to record equipment that was used during preparation, staff behaviour, preparation procedures and unprotected practices. Unprotected practices were defined as risky activities that increased exposure to contamination, such as a staff member touching the corpse and then touching their face, eating lunch without washing hands, or touching other people. The study team was trained on possible risky practices and safety equipment that should be used during corpse preparation. Funeral home staff working during the time of the observation were asked to provide signed consent to be observed.

As part of the study, we conducted interviews with family representatives and funeral home staff who handle corpses. The purpose of the interviews was to explore pre-burial preparation of the corpse that the family might take part in, both before transportation to the funeral home and at the funeral home, and perceptions of infectious disease transmission risk posed by these practices. Because of the complex nature of the study, we were sensitive, empathetic and understanding when approaching participants, especially family members.

Descriptive statistics (frequencies, medians, interquartile ranges (IQRs) and percentages) were used to describe quantitative variables. The primary outcomes assessed included observed equipment, contact with the corpse and exposure to hazardous materials. A structured questionnaire with open-ended and closed-ended questions was administered to explore risk perceptions and family pre-burial preparations. Study participant comments and views were collected and recorded. Content analysis was used to report on participant perceptions.

All interviewed participants were required to sign a consent form. The study was approved by the University of the Witwatersrand Human Research Ethics Committee (Medical) (ref. no. M150355) and the research committees of the provincial departments of health in North West and Gauteng provinces (ref. nos NW_2015RP27_647 and GP_2015RP24_147).

\section{Results}

We approached 34 funeral homes in Klerksdorp and 53 in Soweto. A total of 20 funeral homes out of the 87 approached (23.0\%) agreed to take part in the study, 32.4\% (11/34) in Klerksdorp and $17.0 \%$ $(9 / 53)$ in Soweto. During the study period, one facility in Klerksdorp was not operational because it was awaiting certification; however, the facility was fully equipped, so it was enrolled in the facility assessment only. A total of 147 personnel were reported as employed across the 20 facilities, with a median of 5 (IQR 4 - 8) per facility. Of the enrolled facilities, the majority $(90.0 \%, 18 / 20)$ were privately owned small-to-medium businesses.

\section{Facility assessment}

Most of the facilities across both locations $(75 \%, 15 / 20)$ were based in townships, i.e. underdeveloped urban areas (Table 1). They were located adjacent to schools, residential properties, businesses/offices, private medical practices, industries, shops and food outlets. All the funeral homes had electricity, running water, ventilation and refrigeration. However, none had negative-pressure ventilation and only 5/9 facilities in Soweto (55.6\%) had back-up electricity. Most facilities $(78.9 \%, 15 / 19)$ had multiple separated basins. The median number of bodies stored in a funeral home was 12 (IQR 7 - 20), the figure being slightly higher in Soweto (16, IQR $11-24)$ than in Klerksdorp (8, IQR 6 - 19). The majority of the funeral homes $(75.0 \%, 15 / 20)$ at both locations reported that the average length of stay at the funeral home was 1 week, only $2(10.0 \%)$ reporting stay of $\sim 2$ weeks; 3 (15.0\%) did not answer this question. Refrigeration and body preparation were in the same room in $60.0 \%(12 / 20)$ of the facilities. The funeral home personnel considered their refrigeration storage space to be adequate in $89.5 \%$ of cases (17/19); moreover, 3 facilities indicated that they were in a network that enabled them to refer their corpses for storage if required, and 2 facilities reported having additional refrigerators for periods of high demand.

\section{Safety and equipment usage}

During the facility assessment in the 19 operational facilities, the study team observed varying availability of PPE (Fig. 1). All the facilities had gloves, and some had aprons (73.7\%), face masks (63.2\%), boots $(63.2 \%)$ and gowns (31.6\%). A total of 10 process mappings for body preparation were observed across the two locations, 7 in Klerksdorp and 3 in Soweto. Nine general preparation procedures (body washing and dressing) for family viewing and one embalming procedure were observed. The median time for observed body preparation was 30 minutes (IQR 18 - 35), and the embalming procedure took 50 minutes. When observing the process of preparing corpses, we noted that not all the PPE was used despite its availability. The most commonly used PPE was gloves (100\%), aprons $(80.0 \%)$ and face masks (80.0\%). No unprotected exposures were observed, and at the minimum all personnel wore gloves during the process mapping; however, no one was observed wearing boots, gowns or plastic sleeves for the preparation procedures (Fig. 1).

All the operational facilities reported having biohazardous waste disposal, but three facilities did not separate hazardous waste from normal waste. Biohazardous waste included sharps, PPE, bodywashing cloths and a mortuary body bag. It was disposed of in various ways including burning, collection by a private biohazardous waste management company, burial on the facility premises, and disposal into the general municipal garbage system. In one body 


\begin{tabular}{|c|c|c|c|}
\hline & Klerksdorp $(N=11), n(\%)$ & Soweto $(N=9), n(\%)$ & Overall $(N=20), n(\%)$ \\
\hline \multicolumn{4}{|l|}{ Area } \\
\hline City centre & $5(45.5)$ & 0 & $5(25.0)$ \\
\hline Township & $6(54.5)$ & $9(100)$ & $15(75.0)$ \\
\hline \multicolumn{4}{|l|}{ Running water } \\
\hline Yes & $11(100)$ & $9(100)$ & $20(100)$ \\
\hline No & 0 & 0 & 0 \\
\hline \multicolumn{4}{|l|}{ Electricity } \\
\hline Yes & $11(100)$ & $9(100)$ & $20(100)$ \\
\hline No & 0 & 0 & 0 \\
\hline \multicolumn{4}{|l|}{ Backup electricity } \\
\hline Yes & 0 & $5(55.6)$ & $5(25.0)$ \\
\hline No & $11(100)$ & $4(44.4)$ & $15(75.0)$ \\
\hline \multicolumn{4}{|l|}{ Ventilation } \\
\hline Yes & $11(100)$ & $9(100)$ & $20(100)$ \\
\hline No & 0 & 0 & 0 \\
\hline \multicolumn{4}{|l|}{ Basin } \\
\hline Single multi-purpose & $4 / 10(40.0)$ & 0 & $4 / 19(21.1)$ \\
\hline Multiple separated basins & $6 / 10(60.0)$ & $9(100)$ & $15 / 19(78.9)$ \\
\hline \multicolumn{4}{|l|}{ Refrigeration } \\
\hline Yes & $11(100)$ & $9(100)$ & $20(100)$ \\
\hline No & 0 & 0 & 0 \\
\hline \multicolumn{4}{|l|}{ Refrigeration space } \\
\hline Sufficient & $8 / 10(80)$ & $9(100)$ & $17 / 19(89.5)$ \\
\hline Insufficient & $2 / 10(20)$ & 0 & $2 / 19(10.5)$ \\
\hline
\end{tabular}

preparation observation, a mortuary bag soiled with blood was disposed of in the general waste bin. Most of the rooms (9/10) where bodies were prepared were cleaned after the preparation procedure. However, one incident was observed where the same cloth was used for cleaning floors, body and basins. The main unprotected practice, observed in all 10 body preparation process mappings, was not taking care when removing gloves, and one person did not wash their hands. No needlestick or other injuries were witnessed during the body preparations, and 2/10 staff members (20.0\%) were exposed to blood during this process.

\section{Funeral home staff risk perceptions}

A total of 25 funeral home staff members were interviewed, with a median age of 41 years (IQR 27 - 49) and a median of 4 years (IQR 1.5 - 7) working in the funeral sector. Of those interviewed, $44.0 \%(11 / 25)$ had not completed high school and $12.0 \%$ (3/25) had a tertiary qualification. The majority $(84.0 \%, 21 / 25)$ were male, and $32.0 \%(8 / 25)$ were either the manager or the owner of the funeral home. Other people interviewed were drivers, general workers and embalmers.

The interviewed staff reported that a minimum of two funeral home personnel were usually involved in preparation of

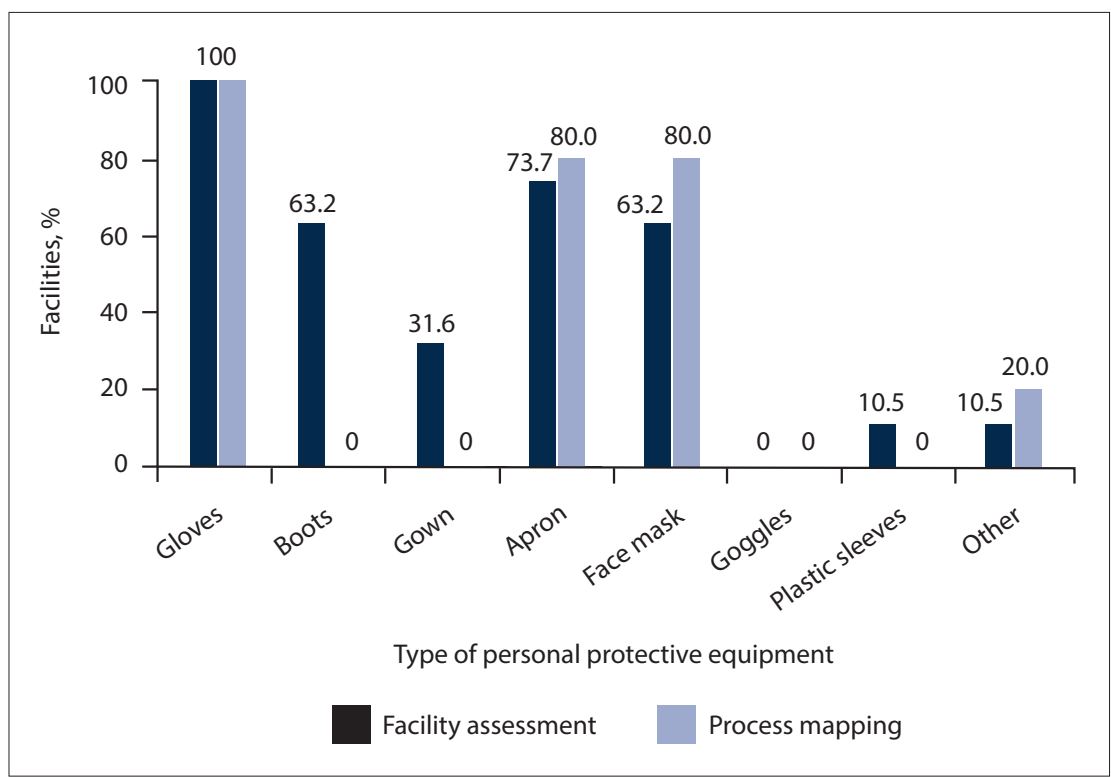

Fig. 1. Safety equipment observed and used across the funeral homes.

a body. The majority stated that safety equipment was used when coming into contact with the body during the process of receiving, unwrapping, storing, embalming and body preparation. PPE most commonly used was gloves, aprons and face masks. A few staff members $(15.8 \%, 3 / 19)$ had received some vaccinations, but only 1 participant confirmed receiving hepatitis $\mathrm{B}$ and tetanus vaccines.
Needlestick and sharps injuries were reported as uncommon, but $8.7 \%$ of staff members $(2 / 23)$ had experienced some skin lacerations and scratches. These were usually managed by washing the wound with a disinfectant and reporting it to management. No staff member knew about any guidelines or procedures for managing injuries. A few were aware of existing guidelines for managing spills. When asked about their 
perceived risk from being exposed to infectious diseases, $27.3 \%$ (6/22) of funeral home staff perceived their job as high risk, while $59.1 \%(13 / 22)$ considered it to be medium/low risk and $15.8 \%(3 / 19)$ perceived no risk. Some thought that while there might be risk, it could be mitigated by wearing the appropriate PPE, while others were concerned that management did not provide adequate protective equipment. Only 1 funeral home reported receiving notifications from government on possible infectious diseases outbreaks.

\section{Family member interviews}

Five family members ( 3 male and 2 female), median age 57 years (IQR 38 - 70), were interviewed for the study. All were siblings of the deceased. One family member reported that the deceased had died at home due to injuries. This family had not come into contact with the body during the preparation for transportation to the funeral home. All 5 of the family members interviewed reported that they had not had direct contact with the deceased during preparation of the body at the funeral home. However, before the start of the body preparation, the family members had been offered the opportunity to partake in this procedure; none had done so, as they realised that they were not emotionally ready. Funeral home personnel were willing to offer the family members PPE (gloves, apron, face masks) if they did wish to be part of the body preparation. The majority of family members $(80.0 \%, 4 / 5)$ asked to view the body after it had been prepared by the funeral home personnel. When the family members were asked about body viewing and burial procedures, they indicated that the body would not be touched or kissed by people attending the funeral.

\section{Discussion}

Our study demonstrated that funeral homes pose a health risk to personnel and communities owing to lack of standardisation of safety equipment used, waste disposal methods and location designations. SA regulations relating to funeral practices specify that corpses can only be prepared on funeral premises with a certificate of competence issued by the government. ${ }^{[18]}$ All funeral homes should provide protective over-clothes consisting of surgical gloves, gumboots, plastic aprons, face masks and linen overcoats. ${ }^{[18]}$ Incorrect or no use of PPE is potentially harmful to funeral home personnel. Compliance with the regulations in both state-owned mortuaries and private funeral homes is inadequate. ${ }^{[19]}$ The Centers for Disease Control and Prevention in 1998 released guidelines for infection control in healthcare personnel outlining the need for PPE, immunisations, and management of job-related illnesses and exposure to infectious hazards. ${ }^{[20]}$ Nwanyanwu et al. ${ }^{[21]}$ reported that $70 \%$ of funeral home personnel interviewed admitted experiencing frequent splashes of body fluids during body preparation, and about $95 \%$ consistently wore gloves; however, fewer personnel reported wearing gowns, aprons, goggles and surgical masks. This is similar to our findings, where the most commonly used equipment was gloves, aprons and face masks.

Between $30 \%$ and $50 \%$ of funeral home personnel have previously been reported as sustaining accidental cuts and puncture wounds, ${ }^{[21,22]}$ considerably higher than the figure in the present study (8.7\%). Waste management was not standardised across the observed facilities, with some disposing waste in the general municipal bins and therefore posing a risk to the surrounding environment. This practice could also put municipal workers at risk of needlestick injuries and exposure. A study in Japan found that about one-third of municipal workers involved in clearing and disposing of waste reported needlestick injuries. ${ }^{[23]}$ Funeral homes should be located at a safe distance from food outlets, schools and open public spaces (e.g. parks) but accessible to biohazardous waste disposal services, in order to avoid contamination in the event of a disease outbreak.

In our facility assessment, we found that two-thirds of funeral homes had the refrigeration units and body preparation table in the same room. This could be because of a recommendation that storage and preparation facilities should be in close proximity to each other to minimise unnecessary handing of bodies ${ }^{[24]}$ Viewing of the body is common practice in many cultures and religions, and some consider that the viewing process assists with grieving and accepting of loss. ${ }^{[25]}$ Although the family members in our study did not come into direct physical contact with the deceased, funeral home personnel should facilitate viewing of the body, while at the same time ensuring that PPE is used and there is minimal exposure.

As we observed in our process mapping, funeral home workers engage in many tasks that could make them vulnerable to infectious hazards, ranging from collection and transport of corpses to storage and preparation. ${ }^{[26]}$ However, the funeral industry in SA is underregulated, with most funeral homes being run as independent businesses with little insight into what safety equipment should be used or how it should be used. While other countries have specific guidelines on handling corpses, ${ }^{[26,27]}$ there is little information on how to analyse and manage exposure to infection in the funeral industry in SA. A study by Omar et al. ${ }^{[17]}$ in Klerksdorp revealed that $30 \%$ of adults who died at home had undiagnosed TB. These bodies were transported to mortuaries or funeral homes where they were prepared for burial. Morbidity and mortality due to TB are high among funeral home personnel. ${ }^{[1-3]}$ They should therefore be provided with regular health assessments and screening for infectious diseases such as TB.

\section{Study limitations}

The number of process mapping and facility assessment observations and family member interviews was small, so it cannot be assumed that the reported findings are applicable to other settings in SA. Social desirability bias could be high owing to the sensitive nature of the research and pre-warning for observations and interviews.

\section{Conclusions}

Our findings suggest that there is a need to improve regulation and monitoring of designated locations, standardisation of safety equipment and waste management for funeral industry services in SA.

\section{Declaration. None.}

Acknowledgements. We thank the study participants and funeral home personnel for agreeing to be part of the study and to answer our questions, the administrative staff at the Perinatal HIV Research Unit for assisting with travel and logistics, and Ms Mbali Nkuta for reviewing and sorting the manuscript references.

Author contributions. AR analysed the qualitative data, and wrote and reviewed the final manuscript. MM conceptualised, developed and implemented the study, analysed and interpreted the data, and wrote and reviewed the manuscript. DM and FM were involved in the acquisition of all data including the facility assessments, process mapping and both sets of interviews, and interpreted the data and reviewed the manuscript. TO made substantial contributions to conception and design of the study, interpretation of data and review of the manuscript. NM and LL made substantial contributions to conception and design of the study and to drafting the manuscript and revising it critically for important intellectual content. All authors read and approved the final manuscript. 
Funding. This study was funded by the Soweto Matlosana SAMRC Collaborating Centre for HIV/AIDS and TB.

\section{Conflicts of interest. None.}

Disclaimer. The opinions expressed herein do not necessarily reflect those of the funder or staff in the funeral homes studied.

1. Davidson SS, Benjamin WH Jr. Risk of infection and tracking of work-related infectious diseases in the funeral industry. Am J Infect Control 2006;34(10):655-660. https://doi.org/10.1016/j.ajic.2006.05.290 2. Morgan O. Infectious disease risks from dead bodies following natural disasters. Rev Panam Salud Publica 2004;15(5):307-312. http://pesquisa.bvsalud.org/portal/resource/pt/mdl-15231077 (accessed 3 July 2019)

3. Kelly N, Reid A. A health and safety survey of Irish funeral industry workers. Occup Med 2011;61(8):570-575. https://doi.org/10.1093/occmed/kqr131

4. World Health Organization. Tuberculosis: Fact Sheet. Geneva: WHO, 2017. http://www.who.int/ mediacentre/factsheets/fs104/en/ (accessed 21 August 2017).

5. Correia JC, Steyl JL, de Villiers HC. Assessing the survival of Mycobacterium tuberculosis in unembalmed and embalmed human remains. Clin Anat 2014;27(3):304-307. https://doi.org/10.1002/ ca. 22355

6. Do AN, Ciesielski CA, Metler RP, Hammett TA, Li J, Fleming PL. Occupationally acquired human HIV epidemic in the United States. Infect Control Hosp Epidemiol 2003:24(2):86-96. https.//do org/10.1086/502178

7. Johnson MD, Schaffner W, Atkinson J, Pierce MA. Autopsy risk and acquisition of human

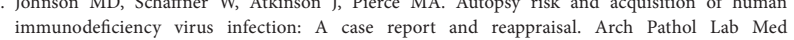
immunodeficiency

8. World Health Organization. Ebola virus disease - Democratic Republic of the Congo. 23 May 2018. http://www.who.int/csr/don/23-may-2018-ebola-drc/en/ (accessed 4 July 2018).

9. Centers for Disease Control and Prevention. 2014 - 2016 Ebola outbreak in West Africa. http://www. cdc.gov/vhf/ebola/outbreaks/2014-west-africa/ (accessed 11 January 2015).

10. Burd EM. Ebola virus: A clear and present danger. J Clin Microbiol 2015;53(1):4-8. https://doi. org/10.1128/JCM.03115-14

11. World Health Organization. How to conduct safe and dignified burial of a patient who has died from suspected or confirmed Ebola or Marburg virus disease. October 2017. http://apps.who.int/iris/ bitstream/10665/137379/1/WHO_EVD_GUIDANCE_Burials_14.2_eng.pdf (accessed 20 June 2015).

12. Richards GA, Weyer J, Blumberg LH. Viral haemorrhagic fevers in South Africa. S Afr Med J 2015;105(9):748-751. https://doi.org/10.7196/SAMJnew.8330

13. Statistics South Africa. Mortality and causes of death in South Africa, 2015: Findings from death notification. Statistical release P0309.3. Pretoria: Stats SA, 2015. https://www.statssa.gov.za/ publications/P03093/P030932015.pdf (accessed 20 June 2019).
14. Joint United Nations Programme on HIV and AIDS (UNAIDS). HIV and AIDS estimates 2015. http:/ www.unaids.org/en/regionscountries/countries/southafrica (accessed 1 September 2017).

15. Statistics South Africa. Soweto. Census 2011. http://census2011.adrianfrith.com/place/798026 (accessed 11 January 2015).

16. Statistics South Africa. Klerksdorp. Census 2011. http://census2011.adrianfrith.com/place/677006 (accessed 11 January 2015).

17. Omar T, Variava E, Moroe E, et al. Undiagnosed TB in adults dying at home from natural causes in a high TB burden setting: A post-mortem study. Int J Tuberc Lung Dis 2015:19(11):1320-1325. https:/ doi.org/10.5588/ijtld.15.0222

18. South Africa. National Health Act No. 61 of 2003: Regulations Relating to the Management of Human Remains. Government Gazette No. 36473, 2013. https://www.gov.za/sites/default/files/gcis document 1201409/36473rg9960gon363.pdf (accessed 20 June 2019).

19. Kubheka T. Ramokgopa: No proper systems in place to manage mortuaries in Gauteng. Eyewitnes News. 2017. https://ewn.co.za/2017/11/23/ramokgopa-no-proper-systems-in-place-to-managemortuaries-in-gauteng (accessed 20 June 2019)

20. Bolyard EA, Tablan OC, Williams WW, et al. Centers for Disease Control and Prevention. Guideline for infection control in health care personnel, 1998. https://www.cdc.gov/hicpac/pdf/infectcontrol98. pdf (accessed 20 June 2019).

21. Nwanyanwu OC, Tabasuri TH, Harris GR. Exposure to and precautions for blood and body fluids among workers in the funeral home franchises of Fort Worth, Texas. Am J Infect Control 1989;17(4):208-212. https://doi.org/10.1016/0196-6553(89)90130-2

22. Beck-Sagué CM, Jarvis WR, Fruehling JA, Ott CE, Higgins MT, Bates FL. Universal precautions and mortuary practitioners: Influence on practices and risk of occupationally acquired infection. J Occup Med 1991;33(8):874-878.

23. Thornton T. Local Government Clinical Waste Management. Victoria, Australia: Deakin University 2007:14

24. Eitzen D, Byard RW. The handling of bariatric bodies. J Forsensic Legal Med 2013;20(1):57-59. https:// doi.org/10.1016/j.jflm.2012.04.032

25. Worden JW. Grief Counselling and Grief Therapy: A Handbook for the Mental Health Practitioner 2nd ed. Abingdon, UK: Routledge, 1991.

26. Health and Safety Executive. Managing infection risks when handling the deceased: Guidance for the mortuary, post-mortem room and funeral premises, and during exhumation. 2018. http://www.hse. gov.uk/pUbns/priced/hsg283.pdf (accessed 2 July 2019).

27. Department of Health, Hong Kong. Precautions for Handling and Disposal of Dead Bodies. 10th ed. Kowloon, 2014. https://www.chp.gov.hk/files/pdf/grp-guideline-hp-ic-precautions_for_handling and_disposal_of_dead_bodies_en.pdf (accessed 20 June 2019).

Accepted 21 January 2019. 